\title{
A INFLUÊNCIA DA IRRIGAÇÃO E ADUBAÇÃO NO RENDIMENTO, TAMANHO E NÚMERO DE TUBÉRCULOS DE BATATA (Solanum tuberosum L.)*
}

\author{
E.J. SCALOPI ** \\ R. SCARDUA*** \\ A.E. KLAR **
}

\begin{abstract}
RESUMO
Neste trabalho foi realizado um estudo para avaliar os efeitos da irrigação e fertilizantes no rendimento, número e tamanho dos tubérculos de batata. A irrigação foi baseada na umidade média do solo quando atingia as tensões de 0,$3 ; 0,6 ; 1,0 ; 3,0$ e 10,0 bares. As doses de fertilizantes aplicadas foram de $40 \mathrm{~kg} / \mathrm{ha}$ de $\mathrm{N}, 80 \mathrm{~kg} / \mathrm{ha}$ de $\mathrm{P}_{2} \mathrm{O}_{5}$ e $40 \mathrm{~kg} / \mathrm{ha}$ de $\mathrm{K}_{2} \mathrm{O}$, sendo a dose $1,40-80-40 \mathrm{~kg} / \mathrm{ha}$ de $\mathrm{N}, \mathrm{P}_{2} \mathrm{O}_{5}$ e $\mathrm{K}_{2} \mathrm{O}$, respectivamente.

Os melhores rendimentos foram alcançados a tensões de umidade do solo menor do que 1,0 bar e as doses 3,4 e 5 de fertilizantes. Não houve diferença significativa no número de tubérculos entre os tratamentos.

Foi observado com aumento na porcentagem de tubérculos maiores nos tratamentos com tensão de umidade de 0,$3 ; 0,6$ e 1,0 bar e doses 4 e 5 de fertilizantes. Por outro lado, foi obtida uma alta porcentagem de pequenos tubérculos a altas tensões de umidade (acima de 1,0 bar) e doses 1 e 2 de fertilizantes.
\end{abstract}

\section{INTRODUÇÃO}

O crescimento das plantas e a produção de tubérculos de batata são intensamente influenciados pelas condições de umidade e fertilidade do solo (ELLISON \& JACOB, 1954; BOX et al., 1963). Os estudos para avaliação das variações dos níveis de umidade e fertilidade do solo tem sido conduzidos para condições específicas de solo, clima e variedade, proporcionando resultados diferentes em relação ao tratamento correspondente aos maiores rendimentos. Assim, BLAKE et al. (1955) não encontraram diferenças significativas na produção de tubérculos, em plantas submetidas a teores mínimos de 67 ou 33\% de água disponível no solo. Resultado semelhante foi encontrado por FULTON \& MURWIN (1955) entre tratamentos com teores mínimos de 75 e $50 \%$ de água disponível. No entanto, atingindo $25 \%$ a produção foi sensivelmente reduzida. Por outro lado, FUEHRING et al. (1966) verificaram redução no rendimento e tamanho dos tubérculos quando apenas $21 \%$ da água disponível havia sido retirada do solo.

* Entregue para publicação em 27/11/1975. Trabalho apresentado na XI Reunião da Sociedade de Olericultura do Brasil, realizada em julho de 1971, em Piracicaba, SP.

* Departamento de Engenharia Rural, ESALQ - Piracicaba, SP.

** Departamento de Engenharia Rural, FCMBB - Botucatu, SP. 
Em condições adequadas de umidade no solo, a aplicação de tertilizantes pode aumentar o rendimento da cultura, aumentando portanto a eficiência de uso dágua. Entretanto, havendo limitações no fornecimento, a quantidade de fertilizante aplicada pode aumentar a utilização de água, devido ao maior desenvolvimento vegetativo das plantas, acelerando o consumo da água disponível do solo, o que poderá reduzir o rendimento, a uma intensidade determinada pela frequência de chuva ou irrigação. Nestas condições haverá redução na eficiência de uso dágua pela cultura (VIETS, 1962). Então, para cada regime hídrico proporcionado às culturas haverá uma quantidade correspondente de fertilizante que condiciona o máximo rendimento. A identificação deste comportamento seria desejável para todas as culturas em todas as condições.

Neste trabalho, os autores pretenderam encontrar, para as condições estudadas, as combinações de água-fertilizante que proporcionassem os maiores rendimentos, associados à maior proporção de tubérculos com tamanho comercialmente desejável.

\section{MATERIAL E MÉTODOS}

Os trabalhos experimentais desenvolveram-se durante o ano de 1970, na Estação Experimental de Botucatu, definida pelas coordenadas geográficas: 22052'55" de latitude sul e 48026'22" de longitude oeste, a uma altitude média de 800 metros. O relevo é normal e ondulado e o solo apresenta as propriedades físicas e químicas anotadas nos Quadros 1 e 2, respectivamente.

QUADRO 1 - Propriedades físicas do solo.

\begin{tabular}{ccccccc}
\hline $\begin{array}{c}\text { Profundidade } \\
(\mathrm{cm})\end{array}$ & $\begin{array}{c}\text { Areia } \\
(\%)\end{array}$ & $\begin{array}{c}\text { Limo } \\
(\%)\end{array}$ & $\begin{array}{c}\text { Argila } \\
(\%)\end{array}$ & $\begin{array}{c}\text { Classificação } \\
\text { textural }\end{array}$ & $\begin{array}{c}\text { Capac. campo } \\
\text { \% de peso de } \\
\text { solo seco }\end{array}$ & $\begin{array}{c}\text { Peso específico } \\
\text { aparente } \\
\mathbf{g ~ c m}^{-3}\end{array}$ \\
\hline \hline $0-20$ & 20,05 & 38,30 & 41,65 & argila & 29,20 & 1,18 \\
$20-40$ & 19,73 & 27,47 & 52,80 & argila & 30,10 & 1,25 \\
\hline
\end{tabular}

QUADRO 2. Propriedades químicas do solo.

\begin{tabular}{lccccccc}
\hline $\begin{array}{c}\text { Profundidade } \\
(\mathrm{cm})\end{array}$ & $\mathrm{pH}$ & $\begin{array}{c}\text { Matéria } \\
\text { orgânica }\end{array}$ & $\begin{array}{c}\mathrm{N} \text { total } \\
(\%)\end{array}$ & \multicolumn{3}{c}{ Teor trocável em e.mg/100 g de terra } \\
\cline { 5 - 9 } & & $(\%)$ & $\mathrm{PO}_{4}^{3-}$ & $\mathrm{K}+$ & $\mathrm{Ca}^{2+}$ & $\mathrm{Mg}^{2+}$ \\
\hline $0-20$ & 5,7 & 2,80 & 0,140 & 0,24 & 0,70 & 4,00 & 1,12 \\
$20-40$ & 5,2 & 2,46 & 0,123 & 0,07 & 0,39 & 2,24 & 0,80 \\
\hline
\end{tabular}


O valor da capacidade de campo foi determinado através do método direto no campo e o peso específico aparente representa uma média entre várias determinações efetuadas com anel volumétrico padrão. A curva característica de umidade do solo (Fig. 1) foi obtida procedendo-se conforme RICHARDS $(1947,1949)$.

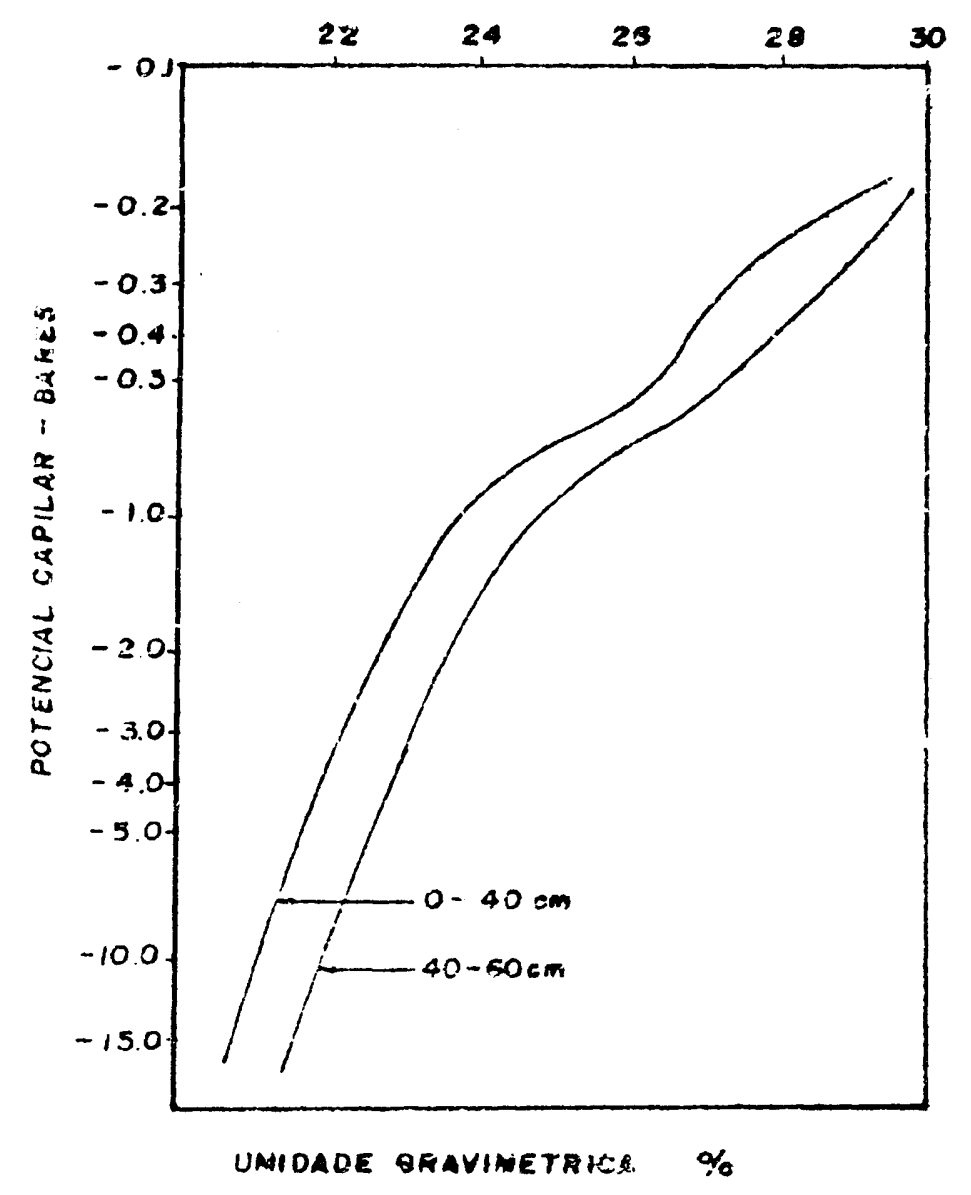

FIG. 1 - Curva característica de umidade do solo.

A freqüência de irrigação para cada tratamento foi estabelecida através de determinações gravimétricas do teor de umidade do solo, a partir de amostragens com trado, de acordo com os resultados de ALLMARAS \& GARDNER (1956).

Admitindo-se os teores de umidade correspondentes à capacidade de campo e ao potencial capilar de $-15,0$ bares, como respectivamente, o limite superior e inferior do intervalo de água disponivel do solo, estabeleceram-se os regimes de umidade proporcionados à cultura definidos pelos tratamentos de irrigação anotados no Quadro 3.

QUADRO 3 - Níveis mínimos médios de água disponível no solo - tratamentos de irrigação.

\begin{tabular}{cccc}
\hline Tratamento & $\begin{array}{c}\text { Pot. capilar } \\
\text { bares }\end{array}$ & $\begin{array}{c}\text { Teor de } \\
\text { umidade } \%\end{array}$ & $\begin{array}{c}\text { \% de água } \\
\text { dispon. }\end{array}$ \\
\hline \hline$I_{1}$ & $-10,0$ & 21,4 & 10 \\
$I_{2}$ & $-3,0$ & 23,7 & 35 \\
$I_{3}$ & $-1,0$ & 26,0 & 60 \\
$I_{4}$ & $-0,6$ & 27,3 & 75 \\
$I_{5}$ & $-0,3$ & 28,7 & 90 \\
\hline
\end{tabular}


O método de irrigação adotado foi sulcos em nível com os bordos fechados, localizados lateralmente às linhas da cultura. A quantidade de água incorporada ao solo por irrigação foi suficiente para elevar o teor de umidade atual à capacidade de campo, a uma profundidade variável de 0,20 a $0,40 \mathrm{~m}$, de acordo com o estágio de desenvolvimento considerado.

A partir da análise química do solo e dos resultados de CARVALHO DIAS (1969), definiram-se cinco doses de $\mathrm{N}, \mathrm{P}_{2} \mathrm{O}_{5}$ e $\mathrm{K}_{2} \mathrm{O}$ como tratamentos de adubação (Quadro 4). $\mathrm{O}$ nitrogênio foi aplicado $1 / 3$ no plantio e $2 / 3$ em cobertura, 20 dias após a emergência das plantas no campo. As quantidades totais de fósforo e potássio foramı aplicadas em pré-plantio.

\begin{tabular}{crrr}
\multicolumn{2}{c}{ QUADRO $4-$ Tratamentos de adubação $-\mathrm{kg} / \mathrm{ha}}$. \\
\hline Tratamento & $\mathrm{N}$ & $\mathrm{P}_{2} \mathrm{O}_{5}$ & \\
\hline $\mathrm{A}_{1}$ & 40 & 80 & $\mathrm{~K}_{2} \mathrm{O}$ \\
$\mathrm{A}_{2}$ & 80 & 160 & 40 \\
$\mathrm{~A}_{3}$ & 120 & 240 & 80 \\
$\mathrm{~A}_{4}$ & 160 & 320 & 120 \\
$\mathrm{~A}_{5}$ & 200 & 400 & 160 \\
\hline
\end{tabular}

Os tratamentos de irrigação e adubação combinados num esquema de ensaio fatorial foram dispostos experimentalmente em blocos ao acaso com duas repetições. Cada parcela constituiu-se de duas linhas de plantio com 4,0 m de comprimento espaçadas de $0,80 \mathrm{~m}$. O plantio efetuou-se em 26/5/1970 seguindo as recomendações de BOOCK (1963), utilizando-se o cultivar Aracy (IAC-2). A diferenciação entre os tratamentos de irrigação foi iniciada após a emergência das plantas no campo. Os tratos culturais e fitossanitários realizaram-se sistematicamente, conforme orientação do Departamento de Fitotecnia - FCMBB.

Visando a posterior análise do tamanho dos tubérculos, separou-se a produção obtida em cinco classes, utilizando-se peneiras com malhas apresentando as seguintes dimensões (BOOCK, 1963):

\begin{tabular}{ll}
\hline Tipo & Dimensões $(\mathrm{mm})$ \\
\hline \hline especial & $50 \times 50$ \\
primeira & $40 \times 40$ \\
segunda & $33 \times 33$ \\
terceira & $28 \times 28$ \\
quarta & $23 \times 23$ \\
\hline
\end{tabular}




\section{RESULTADOS}

a) Produção e número de tubérculos - A colheita das parcelas experimentais, efetuada quatro meses após o plantio, revelou a produção total de tubérculos representada na Fig. 2. A análise de variância e o teste de Tukey aplicados aos dados obtidos revelaram diferenças significativas ao nivel de $1 \%$ de probabilidade entre o tratamento $I_{1}$, ou o tratamento $I_{2}$, e os tratamentos $I_{3}, I_{4}$ e $I_{5}$. Os dois primeiros, por sua vez diferiram entre si ao nível de $5 \%$. Os tratamentos de adubação representados pelas doses $\mathrm{A}_{3}, \mathrm{~A}_{4} \mathrm{e}$ $A_{5}$ apresentaram uma produção de tubérculos significativamente superior ao tratamento $A_{1}$, ao nivel de $1 \%$ de probabilidade. $O$ tratamento $A_{2}$ diferiu do tratamento $A_{1}$, e do tratamento $\mathrm{A}_{5}$, ao nível de $5 \%$. O número de tubérculos produzidos revelou-se estatisticamente semelhante em todos os tratamentos. Os coeficientes de variação foram $9,23 \%$ para a produção e $6,70 \%$ para o número de tubérculos.

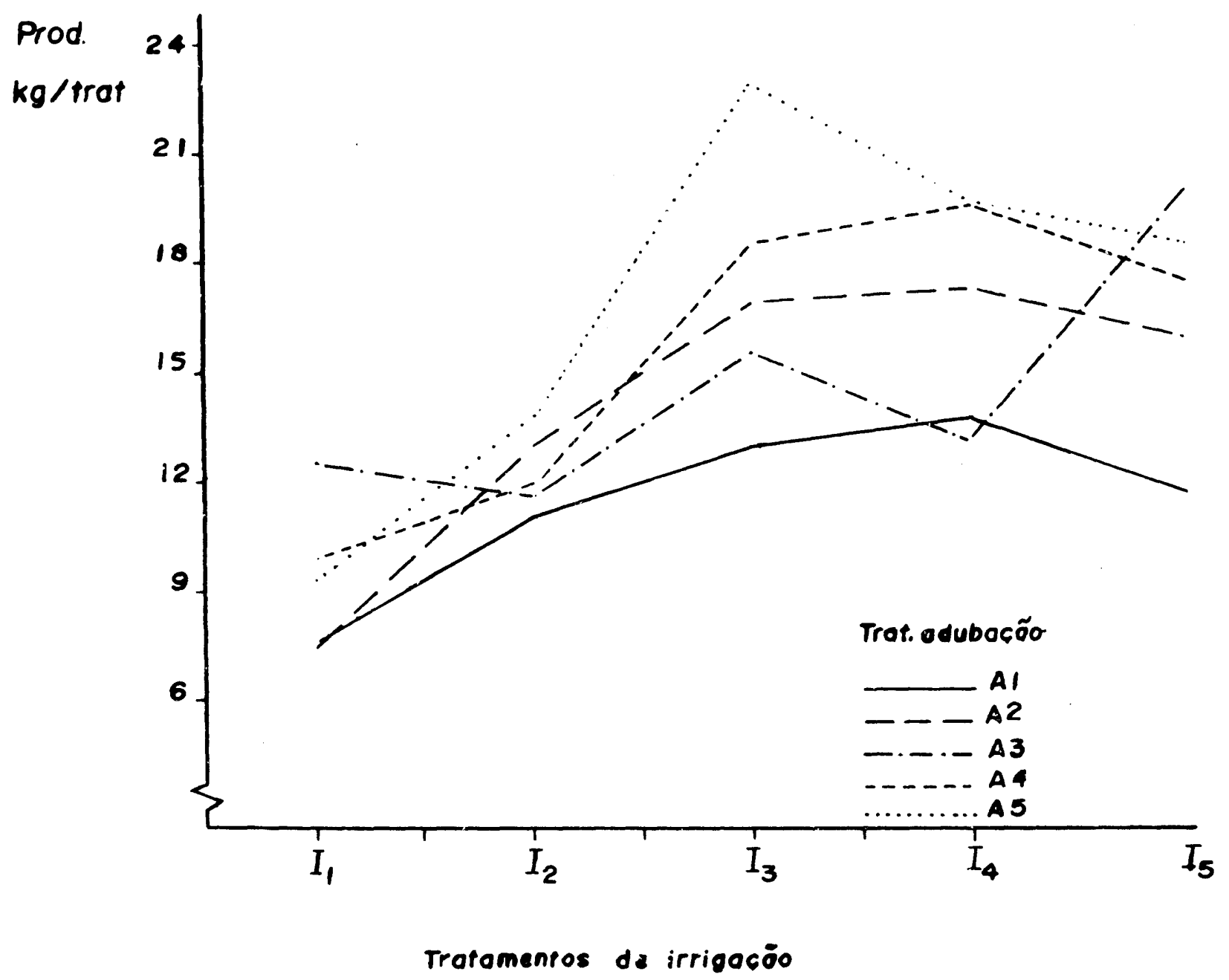

FIG. 2 - Produção total de tubérculos em função dos tratamentos de irrigação e adubação. 
b) Classificação dos tubérculos - $\mathrm{O}$ critério de classificação adotado proporcionou as porcentagens médias de cada tipo em relação à produção total, mostradas nas Figs. 3 e 4. O peso médio dos tubérculos foi $112,0 \mathrm{~g}$ no tipo especial; $69,0 \mathrm{~g}$ no tipo primeira; $38,8 \mathrm{~g}$ no tipo segunda; $14,5 \mathrm{~g}$ no tipo terceira e $3,1 \mathrm{~g}$ no tipo quarta. A análise de variância dos dados e o teste de Tukey aplicado às respectivas médias revelaram os seguintes resultados:

1 - Os tratamentos $I_{1}$ e $I_{2}$ diferiram significativamente dos demais, ao nível de $1 \%$ de probabilidade, nos tipos primeira e segunda.

2 - Nos tipos especial, terceira e quarta, o tratamento $I_{1}$, diferiu significativamente dos demais, a $1 \%$, enquanto que o tratamento $I_{2}$ apresentou-se diferente dos demais a $5 \%$.

3 - A proporção de iubérculos encontrada no tratamento $A_{1}$ e classificados no tipo primeira, foi significativamente inferior ao tratamento $A_{5}$, ao nível de $1 \%$ de probabilidade.

4 - Os tratamentos $A_{1}$ e $A_{2}$ mostraram-se diferentes dos tratamentos $A_{4}$ e $A_{5}$, a $5 \%$, no tipo terceira.

CLASSIFICACÃO

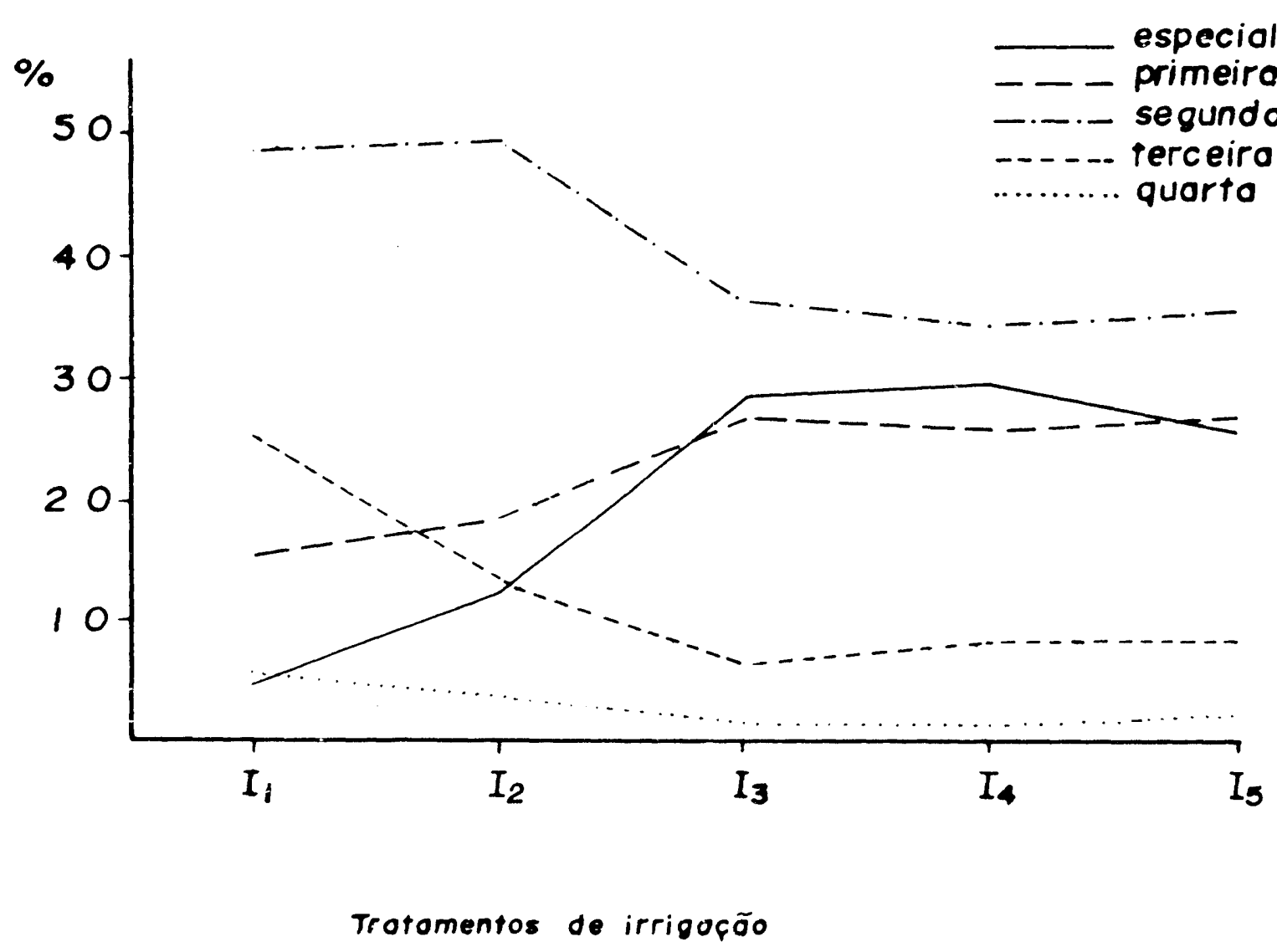

FIG. 3 - Porcentagens médias de cada tipo em relação a produção total de tuberculos, em função dos tratamentos de irrigação. 


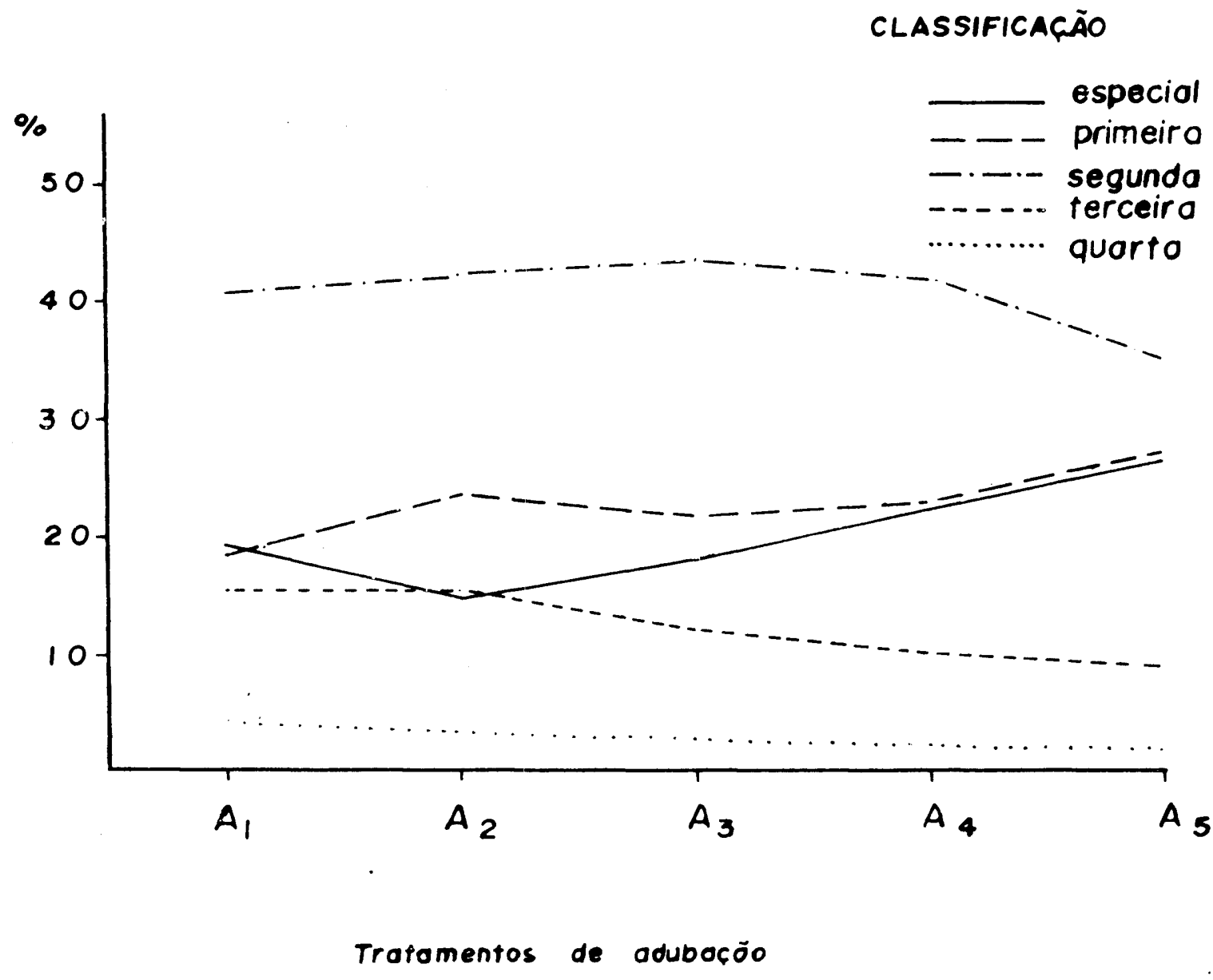

FIG. 4 - Porcentagens médias de cada tipo em relação à produção total de tubérculos, em função dos tratamentos de ad̉ubação.

5 - No tipo quarta foram encontradas diferenças significativas ao nivel de $1 \%$, entre o tratamento $A_{1}$ e os tratamentos $A_{3}, A_{4}$ e $A_{5}$; entre o tratamento $A_{2}$ e os tratamentos $\mathrm{A}_{4}$ e $\mathrm{A}_{5}$ e, entre os tratamentos $\mathrm{A}_{3}$ e $\mathrm{A}_{5}$.

Os coeficientes de variação foram $17,90 \%$ no tipo especial, $8,21 \%$ no tipo primeira, $7,80 \%$ no tipo segunda, $11,53 \%$ no tipo terceira e $7,27 \%$ no tipo quarta.

\section{DISCUSSÃo E CONCLUSÕES}

a) Produção e número de tubérculos - $\mathrm{O}$ decréscimo na produção de tubérculos com o aumento na tensão de umidade do solo, conforme revelam os resultados, tem sido amplamente reconhecido (ELLISON \& JACOB, 1954; FULTON \& MURWIN, 1955; BOX et al., 1963; FUEHRING et al., 1966). Assim, nos tratamentos onde a irrigação impediu que o solo atingisse níveis de água disponível inferiores a $60 \%$, a produção foi sensivelmente superior aos tratamentos com niveis mais reduzidos de umidade. Nestes, podem-se observar relações proporcionais entre o nível mínimo de água disponível e a produção correspondente. A redução do teor de umidade do solo aumenta a tensão com a qual é retida e reduz a condutibilidade hidráulica, diminuindo a intensidade de evapotranspiração (EAGLEMAN \& DECKER, 1963). Isto poderia causar deficit de água na planta e, conseqüentemente, reduzir a produçâo (KRAMER, 1963). 
O efeito da adubação na produção de tubérculos ficou evidenciado nas dosagens $A_{3}, A_{4}$ e $A_{5}$, com resultados significativamente superiores aos tratamentos $A_{2}$ e $A_{1}$. ELLISON \& JACOB (1964) verificaram um efeito altamente significativo de $\mathrm{N}, \mathrm{P}_{2} \mathrm{O}_{5}$ e $\mathrm{K}_{2} \mathrm{O}$ na produção de seis variedades de batata devido à irrigação. Uma análise da Fig. 2 revela que as respostas aos tratamentos de adubação manifestaram-se com maior intensidade nos tratamentos mais irrigados. É interessante notar que irrigações muito freqüentes, procurando manter níveis superiores a $90 \%$ de água disponivel no solo, tendem a diminuir a produção. Nestas condições, de acordo com RATTAM \& TAYLOR (1970), poderia haver redução na aeração de solo e, conseqüentemente, prevalecer condições redutoras que inibiram a mineralização, converteriam o nitrogênio nítrico às formas voláteis e elevariam o pH do solo, alterando inúmeras transformações bioquímicas. Por outro lado, poderia causar mudanças morfológicas e fisiológicas na planta, reduzindo o desenvolvimento do sistema radicular e causando suberização das radicelas, o que diminuiria a permeabilidade das raízes à água e nutrientes. Além disso, a aeração inadequada poderia inibir a translocação de nutrientes na planta. STOCKTON (1962) considera que a irrigação da cultura da batata, baseada nos valores da tensão de umidade do solo inferiores a 0,4 bar pode reduzir a produção e a qualidade dos tubérculos, provavelmente, devido à restrição na aeração em condições de elevados teores de umidade do solo.

A semelhança estatística entre o número de tubérculos obtidos em todos os tratamentos permite estabelecer que esta característica parece manifestar-se independentemente das variações nos fatores estudados. Em conseqüência, as diferenças significativas observadas na produção devem resultar de variações no desenvolvimento dos tubérculos, proporcionados pelos tratamentos de irrigação e adubação. Esta observação será complementada adiante, com os resultados de classificação dos tubérculos.

b) Classificação de tubérculos - Tanto a irrigação como a adubação parecem influir no desenvolvimento de tubérculos de batata. Regimes de umidade procurando manter níveis superiores a $60 \%$ de água disponível no solo tendem a aumentar a proporção de tubérculos maiores, em relação à produção total. Niveis mais reduzidos, ao contrário, acentuaram a proporção de tubérculos pequenos, comercialmente inferiores, como pode ser observado na Fig. 3. O aumento na porcentagem de tubérculos pequenos com a tensão de umidade do solo tem sido observado em inúmeros trabalhos anteriores (FUEHRING et al., 1966; FULTON \& MURWIN, 1955; MACGILLIVRAY, 1950).

$\mathrm{O}$ efeito da adubação, conforme representado na Fig. 4, parece mostrar que dosagens mais elevadas de adubação favorecem a produção de tubérculos de maior tamanho (especial e primeira), enquanto que doses baixas tendem produzir tubérculos pequenos (terceira e quarta). A proporção de tubérculos de tamanho médio (segunda) permaneceu indiferente às dosagens de ${ }^{*}$ adubação utilizadas.

Os resultados de classificação estão de acordo os resultados de produção total e número de tubérculos obtidos. Realmente, não havendo diferenças no número, os tratamentos de irrigação e adubação só poderiam ter proporcionado variações no desenvolvimento dos tubérculos, justificando com isto as diferenças observadas na produção.

Os tratamentos mais convenientes para a cultura da batata, nas condições estudadas, 
estariam associados aos tratamentos intermediários de irrigação $\left(I_{3}\right)$ e adubação $\left(A_{3}\right)$, os quais apresentaram também elevada proporção de tubérculos comercialmente desejáveis. Baseados nos resultados obtidos, pode-se conclurir que os efeitos da adubação parecem estar diretamente relacionados aos regimes de umidade do solo proporcionados à cultura.

\section{SUMMARY}

\section{EFFECTS OF IRRIGATION AND FERTILIZATION ON YIELD, NUMBER AND SIZE OF POTATO TUBERS (Solanum tuberosum L.)}

A study was made on the effects of irrigation and fertilization on the yield, number, and size of potato tubers. Irrigation was based on the mean soil moisture tension of $0.3,0.6,1.0,3.0$ and 10.0 bars. Fertilizer in $40 \mathrm{~kg} / \mathrm{ha}$ of $\mathrm{N}$, and $\mathrm{K}_{2} \mathrm{O}$ and $80 \mathrm{~kg} / \mathrm{ha}$ of $\mathrm{P}_{2} \mathrm{O}_{5}$, being the dosis $1,40-80-40 \mathrm{~kg} / \mathrm{ha}$, of $\mathrm{N}, \mathrm{P}_{2} \mathrm{O}_{5}$, and $\mathrm{K}_{2} \mathrm{O}$, respectively.

Better yields were achieved at soil moisture tensions lower than 1.0 bar and fertilizer dosis 3, 4 and 5. There was no significant difference in the number of tubers among the treatment.

A increase in the percentage of large tubers was observed in the treatments with soil moisture tension of $0.3,0.6$, and 1.0 bar and fertilizer dosis 4 and 5 . On the other hand, a high percentage of small tubers were obtained at higher tensions (over 1.0 bar) and fertilizer dosis 1 and 2.

\section{LITERATURA CITADA}

ALLMARAS, R.R. \& GARDNER, C.O., 1956. Soil sampling for moisture determinations on irrigation experiment. Agron. J., 48(1):15-17.

BLAKE, G.K., BRILL, G.D. \& CAMPBELL, J.C., 1955. Studies on supplemental irrigation of potatoes in New Jersey. Am. Pot. J., 32:327-331.

BOOCK, O.J., 1963. Instruções para a cultura da batatinha. Bolm. técn. Inst. agron. Est. Campinas, $128.68 \mathrm{p}$.

BOX, J.E., SLETTEN, W.H., KYLE, J.H. \& POPE, A., 1963. Effects of soil moisture, temperature, and fertility on yield and quality of irrigated potatoes in the southern plains. Agron. J., 55: $492-494$.

CARVALHO DIAS, C.A., 1969. Adubação da batatinha. Bolm. téc. SCR 45. CATI, Campinas. $17 \mathrm{p}$.

EAGLEMAN, J.R. \& DECKER, W.L., 1965. The role of soil moisture in evapotranspiration. Agron. J., 57(6).626-629.

ELLISON, J.H. \& JACOB, W.C., 1954. Further studies concerning the influence of irrigation on the nitrogen, phosphorus and potash requirements of six potato varieties. Am. Pot. J., 31: 141-151.

FUEHRING, H.D., MAZAHERI, A., BYBORDI, M. \& KHAN, A.K., 1966. Effect of soil moisture depletion on crop yield and stomatal infiltration. Agron. J., 58(2):195-198. 
FULTGN, J.M. \& MURWIN, H.F., 1955. The relationship between available moisture levels and potato yieids. Can. J. agric. Sci., $35 \$ 52-556$.

KRAMER, P.J., 1963. Tension of moisture and plant growth. Agron. J., 55(1):31-35.

MACGILLIVRAY, J.H., 1950. Effect of irrigation on the production of white potatoes. Am. Pot. J., $27: 10-23$.

RATTAM, L. \& TAYLOR, G.S., 1970. Drainage and nutrient effects in a field lysimeter study: II. Mineral uptake by corn. Soil Sc1. Soc. Am. Proc., 34(2):245-248.

RICHARDS, L.A., 1947. Pressure-membrane apparatus, construction and use. Agric. Engng., $28: 451-454,460$.

RICHARDS, L.A., 1949. Methods of measuring soil moisture tension. Soil Sci., 68:95-112.

STOCKTON, J.R., 1962. Potato irrigation studies. Twelfth Nat1. Potato Utiliz. conî.

VIETS, Ji., F.G., 1962. Fertilizers and the efficient use of water. Advances in Agronomy, 14: 223-263. 